\title{
EDITORIAL
}

\section{Molecular Psychiatry 1996: High immediacy index}

The Institute of Scientific Information (ISI) has rel eased their Journal Citation Reports Immediacy Index for 1996, which rates the 'hottest' journals. Molecular Psychiatry had the second highest rate in the field of psychiatry (Table 1), and was rated higher than well-established medical journals, such as Endocrinology, Journal of Clinical Endocrinology and Metabolism, and American Journal of Physiology (Table 1).

The journal Immediacy Index is a measure of how quickly the 'average article' in a journal is cited in the same year it is published. The immediacy index will tell how often articles published in a journal are cited within the same year. Ranking by immediacy index allows one to see which journals received the most citations per current article in the ISI database. This index favors journals which have issues appearing earlier in the year, as there is more time for their papers to be cited in the course of that year. For our first volume, 1996, we had all odds against a high immediacy index. First, our first issue was only distributed in April, which gave little time for our papers to be known and cited in that same year. Second and most importantly, in 1996 Molecular Psychiatry was not cited in Medline, PubMed or Current Contents (our 1996 articles were added to Medline only in 1997). Nevertheless, we reached a very high ranking position in our field. We can only expect that our ranking will increase now that we have been in Medline, PubMed and Current Contents for several months. Such a high immediacy index truly reflects the quality and impact of our papers. We have fulfilled our goals of rigorous review, rapid publication and high visibility. ${ }^{1}$ We would like to thank our readers, contributors, reviewers, and the scientific community at large for the enormous support we have received since our launching in 1996, and for our continued success.

J Licinio Editor
Table 1

Journal Immediacy Index

Non-psychiatric journals:

Cell

6.616

Nature

6.290

New Engl J Med

5.909

Science

4.837

J Clin Invest

1.130

Molecular Psychiatry

0.838

J Clin Endocrinol Metab

0.642

Endocrinology

0.611

Am J Physiol

0.418

Neuroscience journals

Neuron

3.039

J Neurosci

1.374

Molecular Psychiatry $\quad 0.838$

Neuroscience 0.517

Neuroreport $\quad 0.213$

Psychiatric journals

Arch Gen Psychiatry $\quad 1.657$

Molecular Psychiatry $\quad 0.838$

Neuropsychopharmacology $\quad 0.741$

Am J Psychiatry 0.671

Br J Psychiatry $\quad 0.654$

Psychol Med 0.538

Biol Psychiatry $\quad 0.227$

Psychiatry 0.143

Psychiat Res 0.070

Psychiat Clin Neurosci $\quad 0.047$

\section{References}

1 Licinio J. Molecular Psychiatry: The integration of molecular medicine and clinical psychiatry. Mol Psychiatry 1996; 1: 1-3. 